\title{
Gardner's Syndrome in a 75-Year-Old Woman
}

\author{
Galina Vaynsthein ${ }^{1}$, Ludmila Gurlanik ${ }^{2}$ and Arie Markel ${ }^{1}$
}

\begin{abstract}
Familial adenomatous polyposis (FAP) is an inherited disease characterized by the presence of multiple polyps in the colon or other areas of the gastrointestinal tract. In Gardner's syndrome, which is considered by some as a variant of FAP, polyps in the colon present with extracolonic manifestations, such as osteomas, lipomas, fibromas or other soft tissue tumors. In $100 \%$ of all untreated patients, cancer of the large intestine develops before the age of 40 . Subjects with this disorder usually die from complications related to this and other tumors. Older patients surviving this disease only did so after total colectomy was performed.

We describe a 75-year-old patient with the typical lesions of Gardner's syndrome who survived without treatment for the disease for more than 40 years after diagnosis.
\end{abstract}

Key words: Gardner's Syndrome, Familial Adenomatous Polyposis, FAP, colon cancer

(Inter Med 47: 1491-1494, 2008)

(DOI: 10.2169/internalmedicine.47.0997)

\section{Introduction}

Familial adenomatous polyposis (FAP) of the colon is a rare condition characterized by the presence of numerous polyps throughout the large bowel. It is an autosomal dominant inherited disorder due to germline mutations in the adenomatous polyposis coli (APC) tumor suppressor gene on chromosome 5 (1). Gardner's syndrome shares all the features of FAP but extracolonic manifestations are more frequent and generalized. Survival in this disease occurs only when colectomy had been performed previously (2). To the best of our knowledge, the presence of this disease in older untreated patients has not been described before.

\section{Case Report}

A 75-year-old woman was admitted with the clinical picture of sepsis. An underlying urinary tract infection was diagnosed and she was treated with gentamycin and ampicillin. Later, clostridium perfrigens was cultured in the blood. The patient was known to have familiar polyposis of the colon for approximately 40 years. Polyposis of the colon was present also in two sons. The eldest underwent hemicolectomy some years earlier and later died from carcinoma of the colon. The second son underwent partial resection of the colon followed by total colectomy and is alive.

In an hospitalization, two years previously, the patient underwent colonoscopy and gastroduodenoscopy that showed multiple polyps in the colon and duodenum, respectively. A biopsy from the sigma, at that time, indicated villous adenoma.

On physical examination she was in good nutritional state. Lipomas were present over the skin of the arms and on the back of the fingers (Fig. 1). A hard bone mass was present over the mandible (Figs. 2a, 2b) and additional masses were seen over other bones of the face (Fig. 2b). A double contrast barium enema showed multiple polyps of variable size throughout the colon (Fig. 3).

The further course of the hospitalization was uneventful and the patient was discharged after the fever subsided and her condition improved.

\section{Discussion}

Gardner's syndrome (GS) is a familial disorder consisting of gastrointestinal polyposis and osteomas of the skull, mandible and long bones associated with a variety of benign soft tissue tumors $(3,4)$. It is an autosomal dominant disease that begins with colonic adenomatosis and ultimately

${ }^{1}$ Department of Internal Medicine "D”, Rambam Medical Center, Technion, Faculty of Medicine, Haifa, Israel and ${ }^{2}$ Department of Radiology, Rambam Medical Center, Technion, Faculty of Medicine, Haifa, Israel

Received for publication February 7, 2008; Accepted for publication May 2, 2008

Correspondence to Dr. Arie Markel, Markel_ar@clalit.org.il 


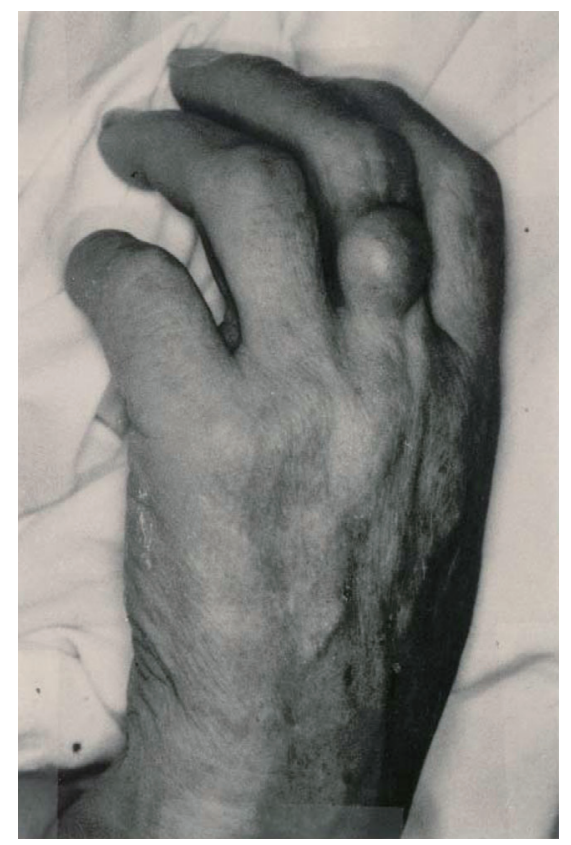

Figure 1. A photography of the left hand of the patient showing a lipoma on the dorsum of the third finger.

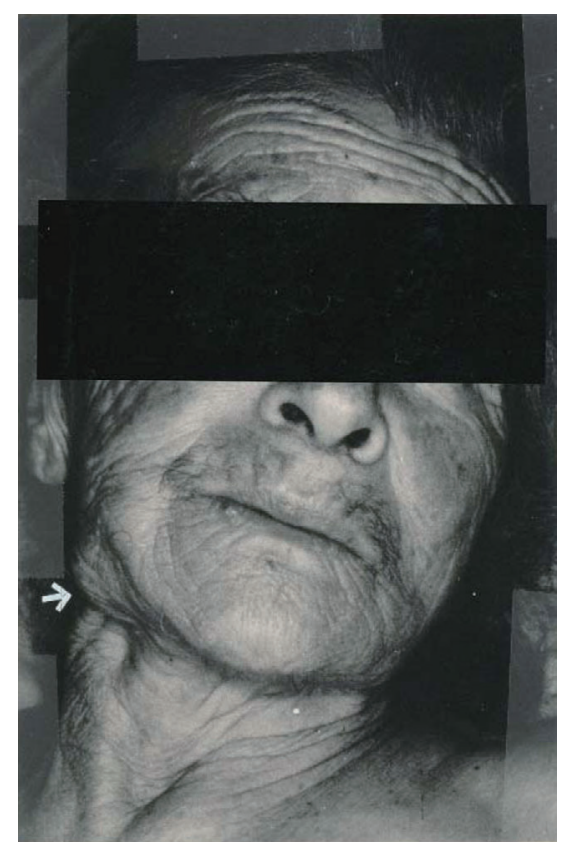

Figure 2a. A photography of the patient's face. A mass is protruding from the right side of the mandible.

progresses to colon cancer (2). The colon is the predominant site of polyposis and the genetic pathological and clinical characteristics of the colonic disease are essentially those of FAP (4). Ninety percent of FAP patients without other stigmata of GS have occult osteomas of the mandible on X-ray and duodenal adenomas. These observations coupled with the abnormalities found on in-vitro testing of skin fibroblasts make a strong argument that FAP and G.S. are vari-

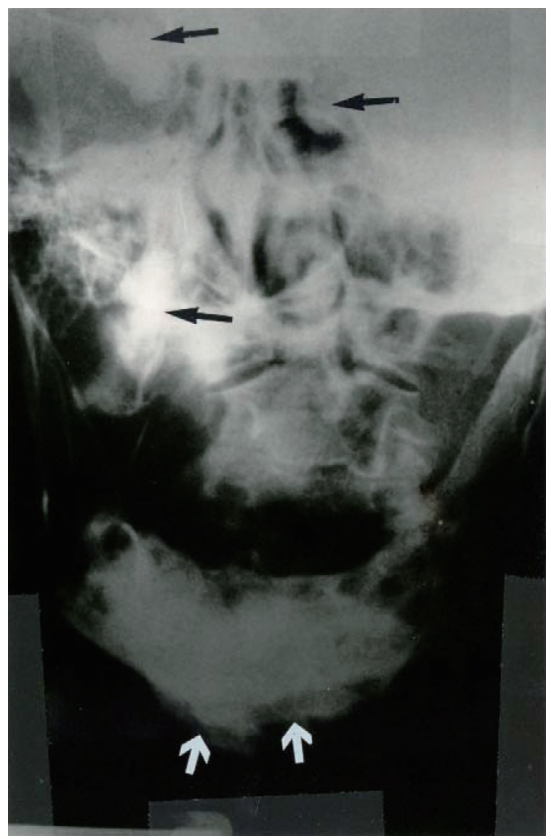

Figure 2b. Radiograph of the face. Multiple osteomas (arrows) are present over the mandible, right maxillary and left paranasal (frontal and ethmoidal) sinuses.

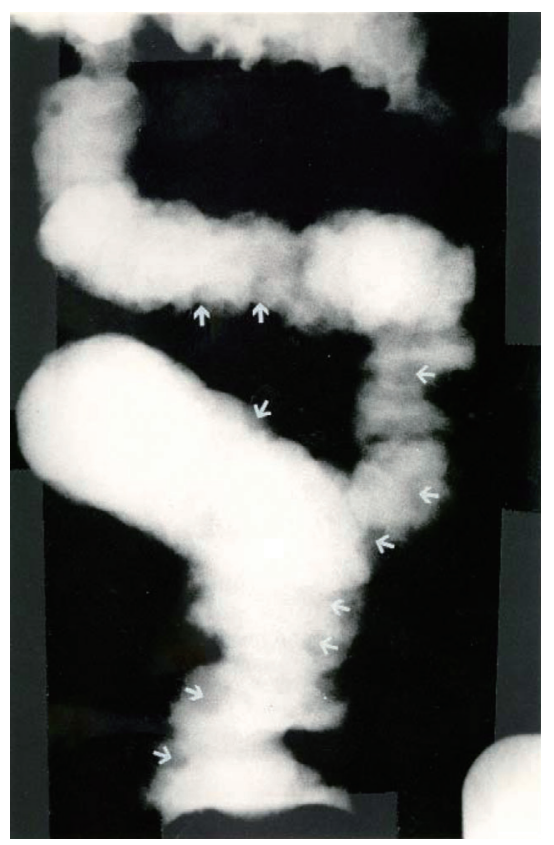

Figure 3. Double contrast barium enema. Multiple filling defects (polyps) of variable size are shown throught the colon.

able expressions of a single disease (4).

Ninety percent of FAP patients without other stigmata of GS have occult osteomas of the mandible on X-ray and duodenal adenomas. Cranial osteomas often precede gastrointestinal manifestations of GS. Therefore, patients presenting with those tumors should be evaluated with genetic testing followed by colonoscopy to prevent the development of colorectal carcinoma. If the diagnosis is positive all family 
members should be evaluated for familial adenomatous polyposis (5). If unchecked, patients with GS inevitably develop intestinal carcinoma, at a much younger age than those with sporadic intestinal carcinoma (5). In the largest series of FAP, the average age of onset of polyps was 25 years, but symptoms did not appear until 33 years (6). The average age for the diagnoses of the adenomas was 36 years and for the diagnoses of cancer 39 years (7). In $100 \%$ of all untreated patients, cancer of the large intestine develops before the age of 40. Hence, prophylactic colectomy is indicated (5). Death from cancer usually occurred by age 42 (4). Cases of longstanding FAP or G.S. not receiving therapy, as in the present case have not been reported previously.

Cancer of colon is found at the time of diagnosis of FAP in $79 \%$ of the cases, but the incidence of cancer in the callup cases (relatives with the disease) is significantly lower (9\%) (4).

Extracolonic manifestations are frequent. Forty to ninety percent of patients may have adenomatous polyps in the stomach, duodenum or in the terminal ileum (2). The risk of dudodenal cancer is increased. Osteomas, in relation to GS are typically found in the skull and the mandible and might be the only extracolonic manifestation related to the disease (8).

GS can occasionally be complicated with intra-abdominal desmoid tumor. These tumors usually remain asymptomatic but can exhibit symptoms due to intestinal, vascular and ureteral compression and obstruction (9) representing difficult management problems. Systemic cytotoxic therapy with doxorubicin and ifosfamide can be useful for patients with complications from intra-abdominal desmoid tumor (10). In life-threatening cases, surgical treatment should be considered as a palliative approach, though the extent of excision remains debatable (9).

Genetic testing is the most efficient mode of identifying gene carriers in a FAP relative. Linkage analysis to markers on chromosome $5 \mathrm{q}$, protein truncation testing, direct sequencing, conformation-sensitive gel electrophoresis, and single-strand, conformation-sensitive gel electrophoresis all have accuracies of $70 \%-90 \%$. Genetic risk assessment should precede the initiation of regular endoscopic screening (5).

A characteristic pigmented fundus lesion representing congenital hypertrophy of the retinal pigment epithelium occurs in $70 \%-80 \%$ of patients with FAP. These ophthalmic manifestations are usually present at birth, largely preceding the development of intestinal polyposis, and are asymptomatic with no malignant potential. The presence of multiple bilateral lesions appears to be a highly specific marker for FAP, making ophthalmological examination an attractive noninvasive and early diagnostic test for at-risk family members, aside from genetic testing (5).

Nonselective or selective cyclooxygenase-2 inhibitor, sulindac or celecoxib, respectively, have been shown to be effective in short-term and long-term studies, to prevent or induce regression of polyps $(4,8,11-13)$, although in the long-term, this treatment does not seem to protect the patients against the development of rectal cancer (4). Surgery remains the only reasonable management option in FAP and G.S. $(4,8)$. Timing and extent of surgery are the major clinical consideration. Because any rectal mucosa that is left behind is at risk for developing subsequent carcinoma, the optimal surgical treatment recommended is to perform total proctocolectomy either with a conventional ileostomy or ileal pouch-anal anastomosis $(4,8)$.

The present patient exhibits the triad of signs of G.S.: intestinal poliposis, bony tumors and soft-tissue lesions. The case is exceptional in that the patient had FAP for 40 years and she did not develop cancer, indicating that some individuals with FAP and G.S. have a benign course and are probably never diagnosed.

\section{References}

1. Marin PJ, Trent JM, Collins SC, Vogelstein B. Cancer genetics. In: Harrison's Principles of Internal Medicine. Kasper DL, Braunwald E, Fauci AS, Hauser S1, Longo DL, Jameson JL, Eds. 16th edition. McGraw-Hill, New York, 2005, 447-453.

2. Rustgi AK. Hereditary gastrointestinal polyposis and nonpolyposis syndromes. N Engl J Med 331: 1694-1702, 1994.

3. Gardner EJ, Richard RC. Multiple cutaneous and subcutaneous lesions occurring simultaneously with hereditary polyposis and osteomatosis. Am J Hum Genet 5: 139-147, 1953.

4. Itzkowitz SH. Colonic polyps and polyposis syndromes. In: Sleisenger \& Fordtran's. Gastrointestinal and Liver Disease. Pathophysiology/Diagnosis/Management. Feldman M, Friedman LS, Sleisenger MH, Eds. 7th Edition. Saunders, Philadelphia, 2002: 2175-2214.

5. Smud D, Augustin G, Kekez T, Kinda E, Majerovic M, Jelincic Z. Gardner's syndrome: Genetic testing and colonoscopy are indicated in adolescents and young adults with cranial osteomas: A case report. World J Gastroenterol 13: 3900-3903, 2007.

6. Burt RW, Samowitz WS. The adenomatous polyp and the hereditary polyposis syndromes. Gastroenterol Clin NA 17: 657-678,
1988.

7. Cruz-Correa M, Giardiello FM. Diagnosis and management of hereditary colon cancer. Hematol/Oncol Clin North Am 17: 539-548, 2003.

8. Nadakumar G, Morgan JA, Silverberg D, Steinhagen RM. Familial polyposis coli: clinical manifestations, evaluation, management and treatment. Mt Sinai J Med 71: 384-391, 2004.

9. Hatzimarkou A, Filippou D, Papadopoulos V, Filippou G, Rizos S, Skandalakis P. Desmoid tumor in Gardner's Syndrome presented as acute abdomen. World J Surg Oncol 4: 18, 2006.

10. Bhama PK, Chugh R, Baker LH, Doherty GM. Gardner's syndrome in a 40-year-old woman: successful treatment of locally aggressive desmoid tumors with cytotoxic chemotherapy. World $\mathbf{J}$ Surg Oncol 4: 96, 2006.

11. Giardello FM, Hamilton SR, Krush AJ, et al. Treatment of colonic and rectal adenomas with sulindac in familial adenomatous polyposis. N Engl J Med 342: 1946-1952, 2000.

12. Cruz-Correa M, Hylind LM, Romans KE, Booker SV, Giardiello FM. Long-term treatment with sulindac in familial adenomatous polyposis: a prospective cohort study. Gastroenterology 122: 641- 
Inter Med 47: 1491-1494, 2008 DOI: 10.2169/internalmedicine.47.0997

$645,2002$.

13. Steinbach G, Lynch PM, Phillips RK, et al. The effect of cele- coxib, a cyclooxygenase-2 inhibitor in familial adenomatous polyposis. N Engl J Med 342: 1946-1952, 2000.

(C) 2008 The Japanese Society of Internal Medicine http://www.naika.or.jp/imindex.html 